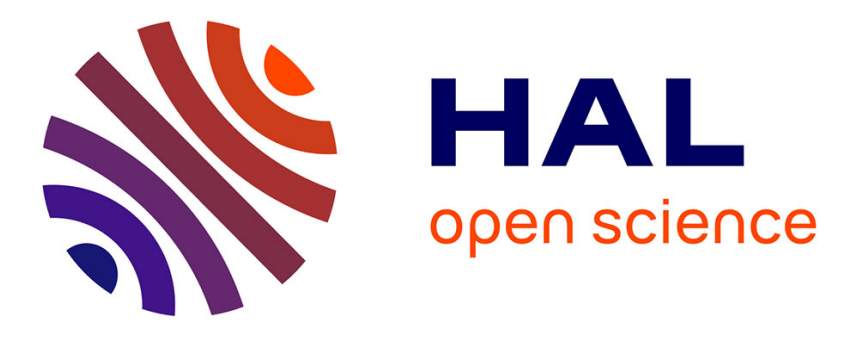

\title{
Transport-related noise exposure in a representative sample of Île-de-France residents: A data-enrichment approach
}

Nina Kreuzberger, Basile Chaix, Ruben Brondeel, Julie Méline, Tarik El

Aarbaoui

\section{To cite this version:}

Nina Kreuzberger, Basile Chaix, Ruben Brondeel, Julie Méline, Tarik El Aarbaoui. Transport-related noise exposure in a representative sample of Île-de-France residents: A data-enrichment approach. Journal of Transport and Health, 2019, 12, pp.220 - 228. 10.1016/j.jth.2019.02.002 . hal-03486277

\section{HAL Id: hal-03486277 \\ https://hal.science/hal-03486277}

Submitted on 20 Dec 2021

HAL is a multi-disciplinary open access archive for the deposit and dissemination of scientific research documents, whether they are published or not. The documents may come from teaching and research institutions in France or abroad, or from public or private research centers.
L'archive ouverte pluridisciplinaire HAL, est destinée au dépôt et à la diffusion de documents scientifiques de niveau recherche, publiés ou non, émanant des établissements d'enseignement et de recherche français ou étrangers, des laboratoires publics ou privés.

\section{(ㄷ)(1) $\$$}

Distributed under a Creative Commons Attribution - NonCommerciall 4.0 International 


\title{
Transport-Related Noise Exposure in a Representative Sample of Île-de-France Residents: A Data-Enrichment Approach
}

\author{
Nina Kreuzberger ${ }^{\mathrm{a}, \mathrm{b}} \quad$ - nina.keuzberger@gmail.com \\ Basile Chaix ${ }^{\mathrm{a}}$ - basile.chaix @iplesp.upmc.fr \\ Ruben Brondeel $^{\mathrm{a}} \quad$ - ruben.brondeel@ umontreal.ca \\ Julie Méline $^{\mathrm{a}} \quad$ - julie.meline@irsn.fr \\ Tarik El Aarbaoui ${ }^{\mathrm{a}, \mathrm{b}}$ - tarik.el-aarbaoui@iplesp.upmc.fr
}

${ }^{a}$ INSERM, Sorbonne Université, Pierre Louis Institute of Epidémiology and Public Health (IPLESP), Nemesis team, F75012 Paris, France

${ }^{\mathrm{b}}$ EHESP School of Public Health, 15 avenue du Professeur Léon-Bernard, 35043 Rennes, France

Address correspondence to:

Nina Kreuzberger

nina.kreuzberger@gmail.com, UMR-S 1136 Inserm - UPMC-Paris 6, Faculté de Médecine Saint-Antoine, 27 rue Chaligny, 75012 Paris, France 

17 the day. $\underline{\text { Transport-Related Noise Exposure in a Representative Sample of Île-de-France }}$

\section{Residents: A Data-Enrichment Approach}

\section{INTRODUCTION}

Noise is an environmental stressor which has been linked to various adverse health outcomes (Babisch, 2011) such as hearing loss (Lie et al., 2016), stress hormone imbalance (Selander et al., 2009), hypertension (van Kempen and Babisch, 2012), sleep disturbance (Hume et al., 2012), long-term elevated risk of stroke (Halonen et al., 2015) and diabetes (Dzhambov, 2015). To minimize the negative impact of noise on health, daily average levels below 50-55 $\mathrm{dB}(\mathrm{A})$ are recommended for the general population (European Environment Agency, 2010).

Many of the associations between noise and health were either assessed in occupational settings (Skogstad et al., 2016) or were based on residential assessments of outdoor noise from modeled noise exposure of selected sources, typically road traffic, railway systems, and aircrafts (Sørensen et al., 2012, Floud et al., 2013). However, noise exposure is not limited to a unique source or a single environment, as people move between places for activities. Therefore, stationary assessment might not accurately reflect personal noise exposure, in particular during

Recent studies took the movement between different microenvironments into account and described personal exposure by following individuals continuously with a noise dosimeter (Taimisto et al., 2013, Kraus et al., 2015, Neitzel et al., 2009). A study done by Kraus et al. (2015) showed that one of the environments with high noise levels was traffic (mean equivalent sound levels $\left(\mathrm{L}_{\text {Aeq }}\right)$ between 74.0 and $78.3 \mathrm{~dB}(\mathrm{~A})$ depending on the transport mode. The average values during transport exceeded the noise level of $70 \mathrm{~dB}(\mathrm{~A})$ which was established for prevention of hearing loss, indicating room for improvements in the protection of the general 
25 population during transport in metropoles. More extensive information on the intensity, duration,

26 and frequency of exposure to noise in a variety of settings would be needed to estimate average

27 daily exposures of a population and evaluate the impact that different scenarios of intervention

28 may have. Unfortunately, studies that deploy noise dosimeters and thus offer very precise

29 information on noise exposure over multiple environments usually result in small sample sizes

30 due to high costs and work-load in data collection and analysis.

To circumvent the limitations of both large-sample residential noise studies based on

32 modelled maps and small studies based on noise dosimeters, the current study proposes a data-

33 enrichment approach to estimate noise levels for a large representative sample from a smaller

34 study sample of the same background population with available noise dosimeter data. A similar

35 approach has been successfully applied to physical activity during transportation by Brondeel et

36 al. (2016). The objectives of the present study were a) to describe personal noise exposure during

37 daily trips with different transport modes in the Île-de-France region, b) to specify a model that

38 predicts personal noise exposure in the dosimeter-based RECORD MultiSensor study, c) to

39 cross-validate this model with a train-test set procedure and d) to apply the developed and

40 validated model to a larger, representative dataset of the same background population (Enquête

41 Globale Transport - EGT) in order to estimate transport-related noise exposure of Île-de-France

42 residents.

43

44 2. MATERIALS AND METHOD

$45 \quad 2.1$ RECORD MultiSensor Study

$46 \quad$ 2.1.1 Sample 
47 As described elsewhere (Chaix et al., 2012), the participants of the RECORD study were 48 recruited in 2007-2008 during free preventative health checkups offered by the French National

49 Health Insurance System for Salaried Workers (CNAMTS) at four different sites in the Île-de50 France region affiliated with the IPC medical Center. The Île-de-France region is the most 51 populated of the 18 regions in France and contains the city of Paris. Inclusion criteria were a) 52 being born between 1928 and 1979, b) residing in one of 112 a priori selected municipalities, and 53 c) being able to complete the questionnaires of the study in French with minimal help. The same 54 participants were followed up and new participants were invited in a second wave of the 55 RECORD study (2011-2012). During this second wave, 286 participants were invited to 56 participate in the RECORD MultiSensor study from September 2013 to June 2015. Written 57 informed consent was obtained from all participants. The RECORD MultiSensor study was 58 approved by the French Data Protection Authority.

\subsubsection{Data collection and processing}

61 For the RECORD study, sociodemographic variables were obtained during the health checkup 62 where participants filled in the IPC medical questionnaire and the RECORD questionnaire. 63 Household income needed to be recoded from a categorical to a continuous variable to be 64 comparable with the EGT income variable. Educational level was summarized in three 65 categories (No diploma of secondary education, diploma of secondary or lower tertiary 66 education, diploma of higher tertiary education). The location of residence was indicated as inner 67 city (Paris), inner suburbs or outer suburbs.

During the MultiSensor study, the participants carried several sensors (wearable class II 69 dosimeter Wed007, ACOEM; GT3X+ accelerometer, ActiGraph; and BT-Q1000XT GPS 
70 receiver, QStarz) from day of inclusion up to day eight. Measurements from day one, 03:00 am

71 up to day eight, 03:00 am were used for analysis. The GPS data of each participant was

72 automatically pre-processed in order to identify visited places and start and end time of each trip

73 stage (Wolf et al., 2004), which is the portion of a trip undertaken with a single transportation

74 mode. These pre-processed GPS tracks were consolidated during a phone mobility survey with

75 the participants, resulting in a detailed timetable of visits at activity places and trips segmented

76 into trip stages for the 7 days of observation, as described in more detail in Brondeel et al. (2016)

77 and Chaix et al. (2014).

78 Participants were instructed to wear the dosimeter at their belt and the microphone close

79 to the ear, and to charge the device during night. Noise was measured continuously as A80 weighted equivalent sound level ( $\left.\mathrm{L}_{\mathrm{Aeq}, 1 \mathrm{~s}}\right)$ per second in a range of 40 to $120 \mathrm{~dB}(\mathrm{~A})$. All $\mathrm{L}_{\text {Aeq,1s }}$

81 values of a trip stage were extracted and summarized average $\mathrm{L}_{\text {Aeq }}$ which is defined as follows:

$$
L_{A e q, T}=10 \log \left(\frac{\sum_{i=1}^{n} 10^{\frac{L i_{A e q}}{10}}}{n}\right)
$$

82 Where:

$83 \quad L_{A e q, T}=$ Averaged equivalent noise level

$84 L L i_{\text {Aeq }}=$ Equivalent noise level for each second

$85 n \quad=$ The total number of one second intervals from $\mathrm{i}$ to $\mathrm{n}$ per trip stage

86 In total, 78 participants of the MultiSensor study carried all devices necessary for inclusion in the

87 prediction model (i.e., the noise dosimeter). However, observations of one participant were 88 excluded due to dosimeter failure.

89

90

\subsection{Global Transport Survey}


91 The global transport survey (EGT; STIF - OMNIL - DRIEA, 2012) is a household survey

92 investigating travel behavior in the Île-de-France region every ten years to assess transport usage

93 in the region, with the latest available data from 2010. Each member of randomly selected

94 households was interviewed face-to-face with regard to all trips performed on the day preceding

95 the interview, resulting in 42,529 surveyed persons. Trips with multiple transport modes were

96 separated into trip stages. The locations of the start and end points of each trip were defined

97 within a grid with a spatial resolution of $100 \mathrm{~m}$ x $100 \mathrm{~m}$ squares, hereafter called tiles. For the

98 current analysis, the age range was limited to the age range of the participants of the RECORD

99 study who carried noise dosimeters (34-74 years old at the date of investigation), resulting in a

100 sample of 18,929 out of 35,511 participants with trips during the past day. A comparison of

101 demographics of the two samples can be found in Table 1. The mean age in the EGT sample

102 retained for the analysis was 51.6 years $(s d=10.9)$. The RECORD MultiSensor study included

103 relatively more men, more people with higher education and more people living in intramural

104 Paris and the inner suburbs.

105

106

Table 1: Overview of the demographic characteristics of the RECORD MultiSensor and EGT study samples

\begin{tabular}{lcc}
\hline Variable & $\begin{array}{c}\text { RECORD } \\
\text { MultiSensor }\end{array}$ & EGT \\
\hline Sample size & 77 & 18,929 \\
$\quad$ Number of participants & 2,183 & 82,046 \\
$\quad$ Number of trips & 3,729 & 207,923 \\
$\quad$ Number of trip stages & & \\
\hline Demographic information & & \\
Age & & \\
\hline
\end{tabular}




\begin{tabular}{|c|c|c|}
\hline $34-43$ years $(\%)$ & 28.6 & 34.0 \\
\hline $44-53$ years $(\%)$ & 32.5 & 27.7 \\
\hline $54-63$ years $(\%)$ & 22.1 & 23.0 \\
\hline $64-74$ years $(\%)$ & 16.9 & 15.3 \\
\hline \multicolumn{3}{|l|}{ Gender } \\
\hline Female $(\%)$ & 36.4 & 52.5 \\
\hline Male $(\%)$ & 63.6 & 47.5 \\
\hline \multicolumn{3}{|l|}{ Educational level } \\
\hline No diploma of secondary education (\%) & 18.2 & 38.1 \\
\hline Diploma of secondary or lower tertiary education (\%) & 31.2 & 27.0 \\
\hline Diploma of higher tertiary education (\%) & 50.6 & 34.9 \\
\hline Household Income ( $€$, mean) & 3940 & 3169 \\
\hline \multicolumn{3}{|l|}{ Location of residence } \\
\hline Inner city (Paris, \%) & 24.7 & 13.9 \\
\hline Inner suburbs (Petite Couronne, \%) & 41.6 & 35.5 \\
\hline Outer suburbs (Grande Couronne, \%) & 33.7 & 50.5 \\
\hline
\end{tabular}

RECORD = Residential Environment and CORonary heart Disease study cohort, MultiSensor branch; EGT =

111 To comply with the Environmental Noise Directive, the non-governmental organization

112 Bruitparif is responsible for integrating modelled noise databases of Île-de-France municipalities.

113 A noise map for the years 2007 to 2011 was constructed to represent the yearly averaged 114 indicator for day, evening and night sound levels $\left(\mathrm{L}_{\mathrm{den}}\right)$ per transport-related noise source (road, 115 railway and air traffic), starting at $55 \mathrm{~dB}(\mathrm{~A})$ in classes of $5 \mathrm{~dB}(\mathrm{~A})$. Additionally, the original 
116 noise layers were gathered and processed to obtain a map that covers the noise range between 117 30-80 dB(A) (Méline et al., 2015, Méline et al., 2013).

The three traffic source layers were combined to produce one integrative noise layer

119 which was used to compute yearly averages of noise levels at the start and end location of each 120 trip stage at a resolution of $100 \mathrm{~m} \times 100 \mathrm{~m}$ tiles in both the RECORD MultiSensor and the EGT 121 studies. ArcMap 10.5 Geographic Information System (ESRI, 2016) and ArcGIS python scripts 122 (Python version 3.4) were used to intersect the required tiles with the polygons of the final noise 123 layer. The process is illustrated in Supplemental material A. For each tile, the mean and quartiles 124 of noise level and the percentage of surface covered by noise levels equal to or higher than 75 $125 \mathrm{~dB}(\mathrm{~A})$ were calculated using the $\mathrm{R}$ software, Version 3.3.2 ( $\mathrm{R}$ Core Team, 2016). These 126 indicators are hereafter referred to as noise map predictors.

\section{$128 \quad 2.4$ Statistical analysis}

129 The 77 RECORD MultiSensor study participants considered in the present study undertook 2537 130 trips consisting of 4365 trip stages. After exclusion of trip stages that used rare transport modes 131 (e.g., skateboard), crossed or were out of the Île-de-France department border, missed more than $13250 \%$ of one-second noise $\mathrm{L}_{\text {Aeq }}$ values or lasted for less than one minute, 3729 trip stages 133 remained in the dataset for analysis.

To ensure consistency with the literature and the Environmental Noise Directive, $\mathrm{L}_{\text {Aeq, }}$ 135 values were used as the outcome for the prediction models per transport mode. A multilevel model (MLM) was specified to predict trip stage level personal noise exposure from trip stage

137 variables. A random intercept was specified at the individual level to account for the hierarchical 138 structure of the data with various trip stages per participant, while variables at the trip stage level 
were added as fixed effects. Person level variables such as sex, age and educational level were excluded due to the small sample size.

For the cross-validation of MLM, the dataset was randomly split in half 10,000 times at the person level to generate pairs of independent datasets, hereafter called train and test sets. The random intercepts that were estimated for each participant in a train set could not be used for the corresponding test set, because participants of one dataset were excluded from the other. Instead, the estimated overall population intercept was used (which is called marginal prediction andused when the final aim is to conduct inference towards a wider population; Welham et al., 2004).

Based on the success of a previous data-enrichment approach by Brondeel et al. (2016), the non-parametric machine learning algorithm 'Random Forests' (RF) with 1000 trees per forest was used in addition to the MLM. RF consist of an ensemble of decision trees that are created by introducing two sources of randomness to the CART algorithm, bagging of observations and subsampling of variables at each tree node (Breiman, 2001). Bagging refers to the construction of each tree based on a bootstrapped subset of approximately two thirds of the unique observations, while at the same time only one-third of model predictors are used per node in the decision trees. An example and more information on RF can be found in Supplemental material $B$ and publications by e.g. Tan et al. (2005), Strobl et al. (2009), and James et al. (2014). The algorithm is more robust against overfitting than single decision trees and has an internal validation mechanism, the out-of-bag $\mathrm{R}^{2}$, i.e., an $\mathrm{R}^{2}$ that is estimated by predictions for each trip stage using every tree for which this trip stage was not used in developing the model. It has been found that the out-of-bag $R^{2}$ can be overestimated when the data is clustered, because trip stages of each given individual are split between those used to grow the forest and those in the out-ofbag sample (Karpievitch et al., 2009). Therefore, as a more robust validation procedure, the RF 
162 models were then cross-validated by splitting the dataset 100 times into a train and test set,

163 containing $70 \%$ and $30 \%$ of the randomly sampled participants, respectively. The number of

164 splits was lower for RF than for MLM due to the complex algorithm which requires longer

165 computation times.

166 As a performance indicator for both model types, the proportion of variance explained

$167\left(\mathrm{R}^{2}\right)$ by the full models in the train sets and test sets were calculated with the following formula 168 to allow comparability:

$$
R^{2}=1-\frac{\sum_{i=1}^{n}\left(y_{i}-\hat{y}_{i}\right)^{2}}{\sum_{i=1}^{n}\left(y_{i}-\bar{y}\right)^{2}}
$$

169 The denominator represents the total variation of the response variable $y$ from the mean, while

170 the numerator represents the variation of $\mathrm{y}$ from the predicted outcome. $\mathrm{R}^{2}$ can take negative

171 values for MLM and RF which indicate that the prediction of the fitted model is worse than the

172 horizontal line drawn through the overall mean noise exposure across all trip stages. Our a priori

173 strategy was to apply the prediction model calibrated from the RECORD MultiSensor Study to

174 the EGT dataset only if the model fit could be considered as good and the predictions accurate.

175 The multilevel model was built with the R package 'nlme' (Pinheiro et al., 2016). Random

176 forests were built with 'randomForest' R package (Liaw and Wiener, 2015) which implements

177 Breiman's RF (Breiman, 2001).

178

179 3. RESULTS

$180 \quad 3.1$ Personal dosimeter and map-based assessments of noise

181 A summary of personal noise exposures according to demographic and trip stage variables can

182 be found in Table 2. The mean duration of a trip stage was 9.7 minutes. The overall average

183 personal noise exposure across all trip stages for $\mathrm{L}_{\mathrm{Aeq}, \mathrm{T}}$ was $71.6 \mathrm{~dB}(\mathrm{~A})(\mathrm{sd}=8.6 \mathrm{~dB}(\mathrm{~A}))$. 
Noise exposure was not very variable between age groups (range: 69.9 - $72.4 \mathrm{~dB}(\mathrm{~A})$ ) and was on average $2 \mathrm{~dB}(\mathrm{~A})$ higher for men than for women. Personal noise values were on average higher in the second half of the week as compared to the beginning of the week and highest 187 during summer compared with other seasons. Expected differences in exposure between 188 transport modes were recorded, with motorbike showing the highest exposure followed by 189 subway trip stages, and then by tram and bike trip stages. Lower personal exposures were documented for car, train, walking and bus trip stages.

Table 2: Descriptive statistics for average equivalent sound levels $\left(L_{A e q, T}\right.$ in $\left.d B(A)\right)$ of trip stages in RECORD, overall and separated by participant and trip stage characteristics

\begin{tabular}{|c|c|c|c|c|}
\hline & & $\mathbf{N}_{\text {Trip }}$ & Mean (sd) $\mathbf{L}_{\text {Aeq, }}$ & $P 25$ - p75 $\mathrm{L}_{\text {Aeq,T }}$ \\
\hline \multicolumn{2}{|l|}{ Overall } & 3729 & $71.6(8.6)$ & $68.0-76.8$ \\
\hline \multirow[t]{4}{*}{ Age } & $34-43$ years & 1097 & $72.0(9.7)$ & $68.1-77.5$ \\
\hline & 44-53 years & 1205 & $72.4(6.6)$ & $68.4-76.6$ \\
\hline & 54-63 years & 806 & $69.9(8.9)$ & $66.8-75.2$ \\
\hline & $64-74$ years & 605 & $71.5(9.4)$ & $68.4-77.4$ \\
\hline \multirow[t]{2}{*}{ Sex } & Female & 1466 & $70.4(10.0)$ & $67.0-76.5$ \\
\hline & Male & 2247 & $72.4(7.5)$ & $68.4-76.9$ \\
\hline \multirow{7}{*}{$\begin{array}{l}\text { Transport } \\
\text { Mode }\end{array}$} & Walking & 2,061 & $70.5(8.6)$ & $66.9-75.6$ \\
\hline & Bike & 143 & $73.5(7.2)$ & $70.7-77.6$ \\
\hline & Motorbike & 155 & $79.5(10.3)$ & $74.7-84.8$ \\
\hline & Car & 720 & $71.2(8.3)$ & $67.4-76.1$ \\
\hline & Bus & 143 & $70.2(6.7)$ & $67.9-73.3$ \\
\hline & Tram & 46 & $73.8(4.6)$ & $72.1-75.8$ \\
\hline & Metro & 332 & $75.1(7.6)$ & $72.9-79.3$ \\
\hline
\end{tabular}




\begin{tabular}{llccc}
\hline & RER, Train & & $71.1(8.0)$ & $68.6-75.1$ \\
\hline $\begin{array}{l}\text { Day of } \\
\text { the week }\end{array}$ & Monday & 113 & $70.5(9.1)$ & $67.6-75.4$ \\
& Tuesday & 583 & $70.5(8.8)$ & $67.1-75.7$ \\
& Wednesday & 618 & $71.6(8.7)$ & $68.2-76.8$ \\
& Thursday & 584 & $73.1(6.6)$ & $68.6-77.4$ \\
& Friday & 594 & $72.4(8.0)$ & $68.1-77.3$ \\
& Saturday & 511 & $72.0(9.5)$ & $68.5-77.7$ \\
& Sunday & 490 & $71.1(9.3)$ & $67.1-76.3$ \\
\hline Season & Spring & 333 & $69.9(8.2)$ & $66.9-74.5$ \\
& Summer & 1359 & $73.7(8.8)$ & $69.4-78.4$ \\
& Autumn & 1126 & $71.8(9.5)$ & $68.2-77.9$
\end{tabular}

RECORD: Residential Environment and CORonary heart Disease study cohort, MultiSensor branch; $\mathrm{N}_{\text {Trip }}=$ Number of trip stages per factor level; $\mathrm{L}_{\text {Aeq,T }}=$ Time-averaged equivalent sound level; sd $=$ Standard deviation; $\mathrm{p} 25=25^{\text {th }}$ percentile; $p 75=75^{\text {th }}$ percentile; ${ }^{\text {a }}$ Regional TER and SNCF trains

\subsection{Multilevel model}

\subsubsection{Model on the full dataset}

200 A comparison of the empty model to predict $\mathrm{L}_{\mathrm{Aeq}, \mathrm{T}}$ with and without participant-level random

201 effects justified the choice of a multilevel model $\left(\chi^{2}=568.73\right.$, df $=1, p<0.0001 ; \Delta$ BIC $=$ 202 560.74). The variance partition coefficient of the multilevel model without fixed effects was 2030.20 , indicating that around $20 \%$ of the variance in noise exposure can be attributed to between204 person variation.

205 The coefficients for the fixed effects and corresponding 95\% confidence intervals $(95 \%$ 206 CI) of the multilevel model can be found in Table 3. The full model with random intercepts 207 could explain $25.4 \%$ of the overall variance in $\mathrm{L}_{\mathrm{Aeq}, \mathrm{T}}$, while the model that ignored random 
208 intercepts resulted in an $\mathrm{R}^{2}$ of 0.10 . Several transport modes, i.e. motorbike, car and metro, 209 showed higher noise exposures than walking. The predicted personal noise exposure $\mathrm{L}_{\mathrm{Aeq}, \mathrm{T}}$ 210 increased by $2.6 \mathrm{~dB}(\mathrm{~A})(95 \% \mathrm{CI}: 0.61$ to $4.58 \mathrm{~dB}(\mathrm{~A}))$ and $3.13 \mathrm{~dB}(\mathrm{~A})(95 \% \mathrm{CI}: 1.15$ to 5.11 $211 \mathrm{~dB}(\mathrm{~A}))$, respectively for a 0 to $100 \%$ change of the noise map predictor. It was found that trip 212 stages starting in the outer suburbs compared to intramural Paris were associated with higher 213 personal noise exposure. Trip stages on Thursdays and Fridays exposed participants to more 214 personal noise compared with Sundays. Afternoons and evenings showed higher exposure than 215 mornings $(\beta=1.19 \mathrm{~dB}(\mathrm{~A}), 95 \% \mathrm{CI}: 0.63$ to $1.76 \mathrm{~dB}(\mathrm{~A})$ and $\beta=1.38,95 \% \mathrm{CI}: 0.48$ to 2.28 $216 \mathrm{~dB}(\mathrm{~A})$, respectively). Each kilometer increase in straight-line distance from start to end of a trip 217 stage resulted in an increase of a bit less than $0.1 \mathrm{~dB}(\mathrm{~A})$. All other variables were not associated 218 with personal noise exposure.

Table 3: Fixed effects of two-level regression model with trip stage variables as fixed effects and person identifier as random effect on the full dataset to predict average equivalent sound levels $\left(L_{A e q, T}\right)$ in $\mathrm{dB}(A)$ 222 from personal dosimetry

\begin{tabular}{lrr}
\hline & Coefficient & 95\% CI \\
\hline Intercept & 67.02 & {$[65.22 ; 68.83]$} \\
Mode: Walking & Reference & \\
Mode: Bike & 1.42 & {$[-0.08 ; 2.92]$} \\
Mode: Motorbike & 5.95 & {$[4.24 ; 7.65]$} \\
Mode: Car & 1.23 & {$[0.44 ; 2.02]$} \\
Mode: Bus & -0.42 & {$[-1.76 ; 0.93]$} \\
Mode: Tram & 1.83 & {$[-0.49 ; 4.15]$} \\
Mode: Metro & 3.68 & {$[2.71 ; 4.64]$} \\
Mode: Train & -0.82 & {$[-2.48 ; 0.83]$}
\end{tabular}


$\%$ noise $>75$, start $^{\mathrm{a}}$

$\%$ noise $>75$ end $^{\mathrm{a}}$

Season: Spring

Season: Autumn

Season: Summer

Season: Winter

Day: Monday

Day: Tuesday

Day: Wednesday

Day: Thursday

Day: Friday

Day: Saturday

Day: Sunday

Rush hour $^{\mathrm{a}}$

Time: Morning

Time: Afternoon

Time: Evening

Time: Night

Air Distance

Paris, start

Inner suburbs, start

Outer suburbs, start

Paris, end

Inner suburbs, end

Outer suburbs, end
$[0.61 ; 4.58]$

3.13

$[1.15 ; 5.11]$

Reference

0.95

$[-0.95 ; 2.85]$

$-0.09$

$[-2.02 ; 1.84]$

0.80

$[-1.00 ; 2.59]$

$-0.72$

$[-1.77 ; 0.34]$

$-0.61$

$[-1.67 ; 0.45]$

0.60

$[-0.46 ; 1.67]$

1.64

$[0.57 ; 2.71]$

1.24

$[0.15 ; 2.33]$

0.93

$[-0.15 ; 2.02]$

Reference

0.41

$[-0.16 ; 0.98]$

Reference

1.19

[0.63; 1.76]

1.38

[0.48; 2.28]

1.10

[-1.84; 4.04]

0.09

[0.02; 0.15]

Reference

0.78

$[-0.59 ; 2.16]$

1.89

[0.48; 3.30]

Reference

0.00

[-1.37; 1.37]

0.64

$[-0.76 ; 2.04]$ 
95\% CI: 95\% confidence interval, $\mathrm{dB}(\mathrm{A})$ : A-weighted decibels; ${ }^{\text {a }}$ percentage of surface within start and end tile of departure covered by polygons representing noise exposure equal to or higher than $75 \mathrm{~dB}(\mathrm{~A}) ;{ }^{\mathrm{b}}$ 7:00h-9:00h and 16:00h-19:00h

\subsubsection{Cross-validation.}

With a division into train and test set at the person level, the average $\mathrm{R}^{2}$ of the 10,000 models on the train sets when using random intercepts was 0.27 (range: 0.14 to 0.40 ). When using the population intercept instead for a prediction in the train set, the average $\mathrm{R}^{2}$ was 0.12 (range: 0.02 to 0.24$)$. In contrast, the average $\mathrm{R}^{2}$ that was obtained by applying each train set model to its corresponding test set was 0.01 (range: -0.77 to 0.14 ), indicating a very low predictive ability for other participants than those based on which the model was estimated. For further post-hoc examination, multilevel models were also estimated in each test set, and the regression coefficients for the transport modes and noise map predictors were compared between each train and test set pair of models.

\subsection{Random Forests}

\subsubsection{Model on the full dataset}

Two versions of RF were built, one including and one excluding person level variables (sex, age, occupation, educational level, household income, and number of people living in a household).

Several noise map predictors were entered into the models (mean, median, $25^{\text {th }}$ and $75^{\text {th }}$ percentile of the proportion of the $100 \mathrm{~m}$ tiles at the start and end of trip stages covered by noise polygons), as random forests are able to deal with multicollinearity of the predictors (Hayes et al., 2015, Strobl et al., 2008). As RF result in slightly different predictions for each run due to the randomness introduced by bagging and random selection of variables at each tree node, RF were checked for consistency of prediction accuracy by iterating each version (one with and one 
without person level variables) 50 times. The model including person level variables obtained an average out-of-bag $\mathrm{R}^{2}$ of 0.37 (range: 0.37 to 0.37 ) and an average train set fit of 0.84 (range: 0.84 to 0.84 ). Excluding the person level variables, the model was still able to result in a prediction accuracy of 0.27 (range: 0.26 to 0.27 ) for the out-of-bag $\mathrm{R}^{2}$ and 0.81 (range: 0.81 to 0.81) of variance explained for the dataset itself. However, it should be noted that the out-of-bag observations originated from the same participants as the observations used to build the trees.

\subsubsection{Cross-validation}

To test if RF can predict noise exposure for new participants, the dataset was split 100 times randomly into a train set (70\% of the sample) and a test set at the person level. For the train set, the RF procedure automatically estimated an $\mathrm{R}^{2}$ based on out-of-bag observations. In addition, we recalculated $\mathrm{R}^{2}$ for the whole train set and for the test set. The average and range of the outof-bag $\mathrm{R}^{2}$, the whole train set $\mathrm{R}^{2}$, and test set $\mathrm{R}^{2}$ per version of the model are shown in Table 4 . The model including the person level variables achieved an out-of-bag $\mathrm{R}^{2}$ of 0.39 (range: 0.26 to 0.48 ) and a good average fit on the train dataset. However, the average $\mathrm{R}^{2}$ for predictions on the test set (for participants that were not considered to grow the model) was 0.01 , ranging from 0.12 to 0.10 . Similarly, the predictions for the test sets of the model with only trip stage variables resulted in an $\mathrm{R}^{2}$ of -0.02 (range: -0.15 to 0.10 ). The predictive ability of the model was thus close to zero and its range was very broad. Based on these results, the estimated models were not applied to obtain noise level estimates in the EGT dataset.

\section{Table 4: Average and range of the out-of-bag $R^{2}$ estimated in the train set $(\%)$, of the $R^{2}$ estimated in the} whole train set $R^{2}(\%)$ and of the test set $R^{2}(\%)$ per version of the model predicting the noise outcome $L_{\text {Aeq, }}$ 


\begin{tabular}{lllllll}
\hline & Mean & Range & Mean & Range & Mean & Range \\
\hline $\begin{array}{l}\text { Model with } \\
\text { person level } \\
\text { variables }\end{array}$ & 0.39 & $0.26 ; 0.48$ & 0.84 & $0.81 ; 0.87$ & 0.01 & $-0.12 ; 0.10$ \\
\hline $\begin{array}{l}\text { Model without } \\
\text { person level } \\
\text { variables }\end{array}$ & 0.29 & $0.18 ; 0.38$ & 0.81 & $0.78 ; 0.85$ & -0.02 & $-0.15 ; 0.10$ \\
\hline
\end{tabular}

\section{4. DISCUSSION}

\section{$273 \quad 4.1$ Summary of the results}

274 The current study aimed to describe noise exposure during daily trips, to build a model that can

275 predict this noise exposure, and to apply the model to a larger sample that comes from the same

276 source population. In line with previous findings in different locations (Kraus et al., 2015,

277 Taimisto et al., 2013, Neitzel et al., 2009), noise exposure summarized as the $\mathrm{L}_{\text {Aeq,T }}$ on average

278 exceeded the recommended level of $70 \mathrm{~dB}(\mathrm{~A})$ for all transport modes. With an average transport

279 time of 93.2 minutes per participant per day, personal transport is a considerable source of noise 280 exposure.

The multilevel model showed that approximately $20 \%$ of the variance in noise exposure

282 in our sample was at the person level. Around $9.6 \%$ of the variance could be explained by the

283 fixed effects, where transport mode, day of the week and time of the day, the noise map

284 predictor, the straight-line distance between start and end tiles were found to be important

285 predictors. The $\mathrm{R}^{2}$, and thus the predictive ability of the models, was relatively low even when

286 estimated for the participants who were used to derive the models. However, our cross-validation

287 procedure splitting the trip stages at the participant level showed that the prediction accuracy was

288 even lower and included negative values when models were applied to the participants who were 
289 not considered to derive the model. These negative values indicate that the mean across all 290 predictions can therefore explain as much of the variance in the data as our model. Although the 291 non-parametric RF can describe the train data itself very well, the out-of-bag $\mathrm{R}^{2}$ (estimated from 292 trip stages from the same participants as those used to derive the model) indicated that RF 293 performed better than MLM but worse than expected. RF estimates were not better than MLM 294 estimates when applied to other participants than those used to derive the models. These 295 inaccurate predictions did not allow us to apply the model to the EGT dataset, therefore objective 296 d could not be realized.

\subsection{Interpretation and limitations}

299 The idea for the current study was based on the successful application of RF for the prediction of 300 the number of minutes spent in moderate-to-vigorous physical activity during trips (Brondeel et 301 al., 2015, Brondeel et al., 2016). Even though comparable datasets and partly the same 302 methodology were used, there are substantial differences in the predicted outcomes which 303 require a different set of predictors. Unfortunately, a limitation inherent to the data-enrichment 304 approach, here from a detailed dosimeter study to a large representative household study, is the 305 necessity to use only predictors available in both datasets. Some potentially relevant factors for 306 noise exposure may have been missed due to the unavailability in either one or both datasets. For 307 example, if we were interested only in the RECORD MultiSensor study participants, additional 308 variables such as the travel speed, the exact distance covered, and information based on more 309 precise coordinates such as GPS tracks in combination with the noise map could have been 310 entered as predictors to allow for more efficient use of data. Although the predictors used in the 311 current MLM were associated with the personal exposure, the coefficient of 3.1 was small for an 
312 increase from 0 to $100 \%$ of the surface of the tile exceeding $75 \mathrm{~dB}(\mathrm{~A})$. We expected the RF to

313 account for the unequal importance of the noise map predictors for the different transport modes

314 (e.g., outdoor road, air, and railway traffic noise may not be meaningful to predict the personal 315 exposure for the underground subway trip stages). In addition, the specific map we used 316 represented the annual average noise exposure without any daily, weekly or seasonal variation.

317 Due to the relatively small participant number, some variables contained numerous factor 318 levels. One of these variables was the specific transport line covered in each of the public 319 transport trips; however, many of these lines occurred with low frequencies in our sample and 320 could thus not be entered into the model, but may have implicitly incorporated information on 321 speed, crowding, environmental factors, and type and age of vehicles typically. For instance, 322 train and subway noise levels are influenced by the presence of squealing noises and public 323 audio system, train type and external (Tabacchi et al., 2011, Soeta and Shimokura, 2011), while 324 car noise differs by car type, opening of windows, type of road, number of intersections, etc. For 325 the same reason, person level demographic variables were excluded, which could contain 326 valuable information on behavioral aspects linked to noise exposure. The person-level clustering 327 indicates that there may be some factors at the individual level that influence noise exposure and 328 may explain the non-generalizability of estimated associations to participants who were 329 unknown to the model. One major influence potentially arose from speech because some 330 participants may preferably perform their trips in the company of friends or relatives, and 331 contribution of speech to overall noise levels is dependent on the background levels (Ryherd et 332 al., 2012), increasing unpredictability of the measurements. Other sources of person level 333 variation, dependent on the transport mode, may be route and speed preferences, population 334 density and other characteristics of areas commonly visited, vehicle type, sound system usage, 
335 and driving style (Mikulec et al., 2011). Future prediction models based on a larger dataset may

336 show if the transport line and person level predictors can capture some of the variability in noise 337 exposure.

338 Due to this person level variation, RF were tested for prediction because they are known 339 to capture complex interactions without explicit specification and are commonly used for 340 clustered data (Karpievitch et al., 2009). Therefore, the huge difference between the out-of-bag 341 estimate and the test set prediction (on independent participants) was unexpected. Martin (2015) 342 showed that random forests based on the CART algorithm performed poorly in his simulated 343 condition with a high intra-class correlation of 0.30 and a small sample size (20 clusters with 15 344 observation each) (Martin, 2015), resulting in negative values for $\mathrm{R}^{2}$. The explanation of his 345 results adapted to our findings may sound as follows: the trip stages undertaken by a given 346 participant resemble each other more than when compared with the trip stages by other 347 participants. Therefore, when a tree in a forest is exposed to trip stages of a participant, its 348 knowledge is higher for other trip stages of this participant than for trip stages of other 349 participants. As a consequence, the RF majority vote is more adapted to the participants used for 350 forest construction than for new participants (Martin, 2015).

Predictions for the known participants was not outstanding, possibly due to the lack of 352 specificity of the predictors as outlined before, but potentially also due to the way noise exposure 353 was summarized. We chose the $\mathrm{L}_{\mathrm{Aeq}, \mathrm{T}}$ due to its comparability with current regulations. 354 However, noise exposure expressed as a single value may not describe the variation of 355 soundscapes between microenvironments sufficiently, as the $\mathrm{L}_{\text {Aeq,T }}$ can take the same value for 356 different patterns of exposure. It is possible that different transport modes have very diverse 357 patterns of noise exposure in regard to the frequency bands, rhythm, and noise level peaks. Noise 
358 summary measures with different meanings are for example the number of noise events or

359 percentiles of one-second interval $\mathrm{L}_{\mathrm{Aeq}}$ values such as $\mathrm{L}_{\mathrm{A} 95}$ and $\mathrm{L}_{\mathrm{A} 5}$ (Can et al., 2016). More

360 detailed noise data will be available from a currently ongoing study (MobiliSense) in our lab,

361 which may allow for more discriminable summary measures in the future. Data and scripts can

362 be provided upon request.

363

$364 \quad 4.3$ Conclusion

365 In line with previous studies, the current study found that noise exposure during daily travels is 366 in general high for all transport modes. While models with moderate prediction ability for the 367 participants used to develop the models could be built based on both MLM and RF, the 368 prediction accuracy for other participants was low. Accordingly, we decided to not conduct a 369 prediction of noise levels for the trip stages of the large representative EGT sample. The results 370 may be explained by limitations in the predictors that were used, by the small sample size of the 371 model development set, and by the way noise was summarized. 


\section{References}

Babisch, W. 2011. Cardiovascular effects of noise. Noise and Health, 13, 201-204. doi:10.4103/14631741.80148

Breiman, L. 2001. Random forests. Machine Learning, 45. doi:10.1023/a:1010933404324

Brondeel, R., Pannier, B. \& Chaix, B. 2015. Using GPS, GIS, and accelerometer data to predict transportation modes. Medicine and Science in Sports and Exercise, 47, 2669-2675. doi:10.1249/mss.0000000000000704

Brondeel, R., Pannier, B. \& Chaix, B. 2016. Associations of socioeconomic status with transportrelated physical activity: combining a household travel survey and accelerometer data using random forests. Journal of Transport \& Health, 3, 287-296. doi:10.1016/j.jth.2016.06.002

Can, A., Aumond, P., Michel, S., De Counsel, B., Ribeiro, C., Botteldooren, D. \& Lavandier, C. Comparison of noise indicators in an urban context. 45th International Congress and Exposition on Noise Control Engineering (Inter-noise 2016), 2016 Hambourg, Germany. 5678-5686. (retrieved from: https://hal.archives-ouvertes.fr/hal01373857/file/doc00025834.pdf; last accessed 01.02.2019)

Chaix, B., Kestens, Y., Bean, K., Leal, C., Karusisi, N., Meghiref, K., Burban, J., Fon Sing, M., Perchoux, C., Thomas, F., Merlo, J. \& Pannier, B. 2012. Cohort profile: residential and non-residential environments, individual activity spaces and cardiovascular risk factors and diseases - the RECORD cohort study. International Journal of Epidemiology, 41, 1283-1292. doi:10.1093/ije/dyr107

Chaix, B., Kestens, Y., Duncan, S., Merrien, C., Thierry, B., Pannier, B., Brondeel, R., Lewin, A., Karusisi, N., Perchoux, C., Thomas, F. \& Méline, J. 2014. Active transportation and public transportation use to achieve physical activity recommendations? A combined GPS, accelerometer, and mobility survey study. International Journal of Behavioral Nutrition and Physical Activity, 11, 124. doi:10.1186/s12966-014-0124-x

Dzhambov, A. 2015. Long-term noise exposure and the risk for type 2 diabetes: a meta-analysis. Noise and Health, 17, 23-33. doi:10.4103/1463-1741.149571

Esri 2016. ArcGIS Desktop 10.5. Redlands, CA: Environmental Systems Research Institute.

European Environment Agency 2010. Good practice guide on noise exposure and potential health effects. Copenhagen: European Environment Agency. (Retrieved from: https://www.eea.europa.eu/publications/good-practice-guide-on-noise; last accessed 02.02.2019)

Floud, S., Blangiardo, M., Clark, C., De Hoogh, K., Babisch, W., Houthuijs, D., Swart, W., Pershagen, G., Katsouyanni, K., Velonakis, M., Vigna-Taglianti, F., Cadum, E. \& Hansell, A. L. 2013. Exposure to aircraft and road traffic noise and associations with heart disease and stroke in six European countries: a cross-sectional study. Environmental Health, 12, 89. doi:10.1186/1476-069X-12-89

Halonen, J. I., Hansell, A. L., Gulliver, J., Morley, D., Blangiardo, M., Fecht, D., Toledano, M. B., Beevers, S. D., Anderson, H. R., Kelly, F. J. \& Tonne, C. 2015. Road traffic noise is associated with increased cardiovascular morbidity and mortality and all-cause mortality in London. European Heart Journal, 36, 2653-2661. doi:10.1093/eurheartj/ehv216

Hayes, T., Usami, S., Jacobucci, R. \& Mcardle, J. J. 2015. Using Classification and Regression Trees (CART) and random forests to analyze attrition: results from two simulations. Psychology and Aging, 30, 911-929. doi:10.1037/pag0000046

Hume, K., Brink, M. \& Basner, M. 2012. Effects of environmental noise on sleep. Noise and Health, 14, 297-302. doi:10.4103/1463-1741.104897

James, G., Witten, D., Hastie, T. \& Tibshirani, R. 2014. An Introduction to Statistical Learning: with Applications in $R$, Springer Publishing Company, Incorporated. 
Karpievitch, Y. V., Hill, E. G., Leclerc, A. P., Dabney, A. R. \& Almeida, J. S. 2009. An introspective comparison of random forest-based classifiers for the analysis of cluster-correlated data by way of RF++. PLOS ONE, 4, e7087. doi:10.1371/journal.pone.0007087

Kraus, U., Breitner, S., Hampel, R., Wolf, K., Cyrys, J., Geruschkat, U., Gu, J., Radon, K., Peters, A. \& Schneider, A. 2015. Individual daytime noise exposure in different microenvironments. Environmental Research, 140, 479-487. doi: 10.1016/j.envres.2015.05.006

Liaw, A. \& Wiener, M. 2015. 'randomForest' - Breiman and Cutler's Random Forests for Classification and Regression. CRAN, R package version 4.6-12. (Retrieved from: https://cran.r-project.org/web/packages/randomForest/randomForest.pdf; last accessed: 02.02.2019)

Lie, A., Skogstad, M., Johannessen, H. A., Tynes, T., Mehlum, I. S., Nordby, K.-C., Engdahl, B. \& Tambs, K. 2016. Occupational noise exposure and hearing: a systematic review. International Archives of Occupational and Environmental Health, 89, 351-372. doi:10.1007/s00420-0151083-5

Martin, P. D. 2015. Efficiently exploring multilevel data with recursive partitioning. Dissertation, University of Virginia. (Retrieved from: https://dpmartin42.github.io/extras/dissertation.pdf; last accessed: 02.02.2019)

Méline, J., Van Hulst, A., Thomas, F. \& Chaix, B. 2015. Road, rail, and air transportation noise in residential and workplace neighborhoods and blood pressure (RECORD Study). Noise and Health, 17, 308-319. doi:10.4103/1463-1741.165054

Méline, J., Van Hulst, A., Thomas, F., Karusisi, N. \& Chaix, B. 2013. Transportation noise and annoyance related to road traffic in the French RECORD study. International Journal of Health Geographics, 12, 44. doi: 10.1186/1476-072x-12-44

Mikulec, A. A., Lukens, S. B., Jackson, L. E. \& Deyoung, M. N. 2011. Noise exposure in convertible automobiles. Journal of Laryngology and Otology, 125, 121-125. doi:10.1017/s0022215110002355

Neitzel, R., Gershon, R. R. M., Zeltser, M., Canton, A. \& Akram, M. 2009. Noise levels associated with New York City's mass transit systems. American Journal of Public Health, 99, 1393-1399. doi:10.2105/ajph.2008.138297

Pinheiro J, Bates D, Debroy S, Sarkar D \& R Core Team, 2016. nlme: Linear and Nonlinear Mixed Effects Models. CRAN, R package version 3.1-128. (Retrieved from: https://cran.rproject.org/web/packages/nlme/nlme.pdf; last accessed: 02.02.2019)

R Core Team, 2016. R: A language and environment for statistical computing. Foundation for Statistical Computing, Vienna, Austria.

Ryherd, S., Kleiner, M., Waye, K. P. \& Ryherd, E. E. 2012. Influence of a wearer's voice on noise dosimeter measurements. The Journal of the Acoustical Society of America, 131, 1183-1193. doi:10.1121/1.3675941

Selander, J., Bluhm, G., Theorell, T., Pershagen, G., Babisch, W., Seiffert, I., Houthuijs, D., Breugelmans, O., Vigna-Taglianti, F., Antoniotti, M. C., Velonakis, E., Davou, E., Dudley, M.-L. \& Järup, L. 2009. Saliva cortisol and exposure to aircraft noise in six European countries. Environmental Health Perspectives, 117, 1713-1717. doi:10.1289/ehp.0900933

Skogstad, M., Johannessen, H. A., Tynes, T., Mehlum, I. S., Nordby, K. C. \& Lie, A. 2016. Systematic review of the cardiovascular effects of occupational noise. Occupational Medicine, 66, 10-16. doi:10.1093/occmed/kqv148

Soeta, Y. \& Shimokura, R. 2011. The impact of external environments on noise inside a train car. Noise Control Engineering Journal, 59, 581-590. doi:10.3397/1.3628526

Sørensen, M., Andersen, Z. J., Nordsborg, R. B., Jensen, S. S., Lillelund, K. G., Beelen, R., Schmidt, E. B., Tjønneland, A., Overvad, K. \& Raaschou-Nielsen, 0. 2012. Road traffic noise and incident myocardial infarction: a prospective cohort study. PLOS ONE, 7, e39283. doi:10.1371/journal.pone.0039283 
Stif - Omnil - Driea 2012. Enquête globale transport (EGT): La mobilité en Île-de-France. (Retrieved from : http://www.omnil.fr/IMG/pdf/egt2010_enquete_globale_transports_-_2010.pdf; last accessed: 02.02.2019)

Strobl, C., Boulesteix, A. L., Kneib, T., Augustin, T. \& Zeileis, A. 2008. Conditional variable importance for random forests. BMC Bioinformatics, 9. doi:10.1186/1471-2105-9-307

Strobl, C., Malley, J. \& Tutz, G. 2009. An introduction to recursive partitioning: rationale, application and characteristics of classification and regression trees, bagging and random forests. Psychological Methods, 14, 323-348. doi:10.1037/a0016973

Tabacchi, M., Pavon, I., Ausejo, M., Asensio, C. \& Recuero, M. 2011. Assessment of noise exposure during commuting in the Madrid subway. Journal of Occupational and Environmental Hygiene, 8, 533-9. doi:10.1080/15459624.2011.600237

Taimisto, P., Yli-Tuomi, T., Pennanen, A., Vouitsis, I., Samaras, Z., Keuken, M. P. \& Lanki, T. Noise exposure during commuting in three European cities. Internoise, 2013 Insbruck, Austria. 15. (Retrieved from: https://repository.tudelft.nl/view/tno/uuid\%3A9b2682ff-5a95-4e80a8f6-fc60a2df1523; last accessed: 02.02.2019)

Tan, P.-N., Steinbach, M. \& Kumar, V. 2005. Introduction to Data Mining, (First Edition), AddisonWesley Longman Publishing Co., Inc.

Therneau, T., Atkinson, B. \& Ripley, B. 2015. Package 'rpart': Recursive Partitioning and Regression Trees. CRAN, R package version 4.1-10. (Retrieved from: https://cran.rproject.org/web/packages/rpart/rpart.pdf; last accessed: 02.02.2019)

Van Kempen, E. \& Babisch, W. 2012. The quantitative relationship between road traffic noise and hypertension: a meta-analysis. Journal of Hypertension, 30, 1075-1086. doi:10.1097/HJH.0b013e328352ac54

Welham, S., Cullis, B., Gogel, B., Gilmour, A. \& Thompson, R. 2004. Prediction in linear mixed models. Australian \& New Zealand Journal of Statistics, 46, 325-347. doi:10.1111/j.1467842X.2004.00334.x

Wolf, J., Schönfelder, S., Samaga, U., Oliveira, M. \& Axhausen, K. 2004. Eighty weeks of Global Positioning System traces: approaches to enriching trip information. Transportation Research Record: Journal of the Transportation Research Board, 1870, 46-54. doi:10.3141/1870-06 


\section{A. Distribution of combined road, rail and air traffic noise in the Île-de-France region.}
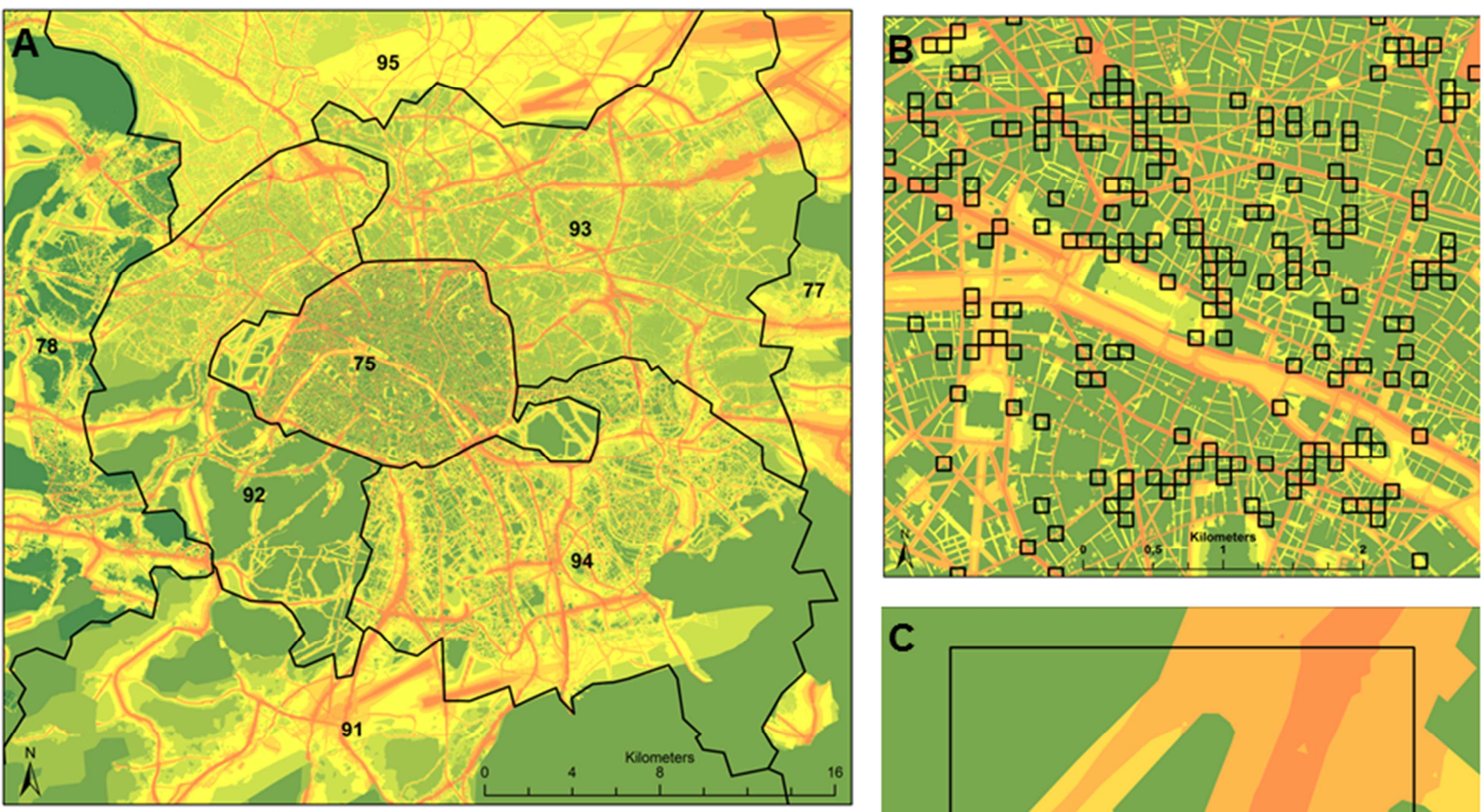

Combined road, rail and air traffic

noise in the lle-de-France region

$35.40 \mathrm{~dB}(\mathrm{~A})$

$40.45 \mathrm{~dB}(\mathrm{~A})$

$45.50 d B(A)$

$55.60 \mathrm{~dB}(\mathrm{~A})$

$60.65 d B(A)$

$65.70 \mathrm{~dB}(\mathrm{~A})$

$70.75 \mathrm{~dB}(\mathrm{~A})$

$75.80 \mathrm{~dB}(\mathrm{~A})$
$80.85 \mathrm{~dB}(\mathrm{~A})$

The lle-de-France region

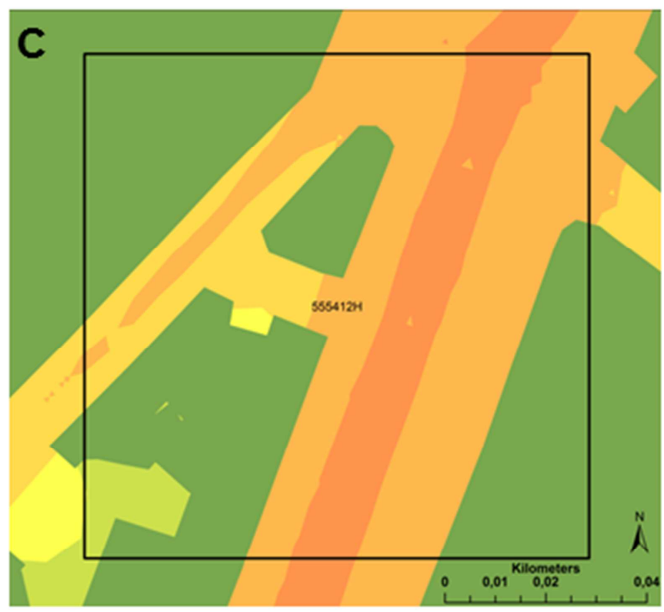

508 A shows an overview of the noise distribution and is zoomed towards the inner suburbs (departments 92, 93, 94) and

509 Paris (75). B zooms further in and shows a part of the map within Paris. In this map, the $100 \mathrm{~m} \times 100 \mathrm{~m}$ start- and

510 end-tiles of trip stages undertaken by the RECORD participants within the area are marked with black borders. C

511 illustrates a single tile. To calculate noise predictors from the tile, the proportion of area covered by each noise

512 polygon (e.g. for 75-80 dB(A) in colored in dark orange) was extracted with ArcGIS 10.5 with help of the intersect

513 tool. After export, the mean and median noise level were calculated from this surface information per tile with the

514 Software R and RStudio. 


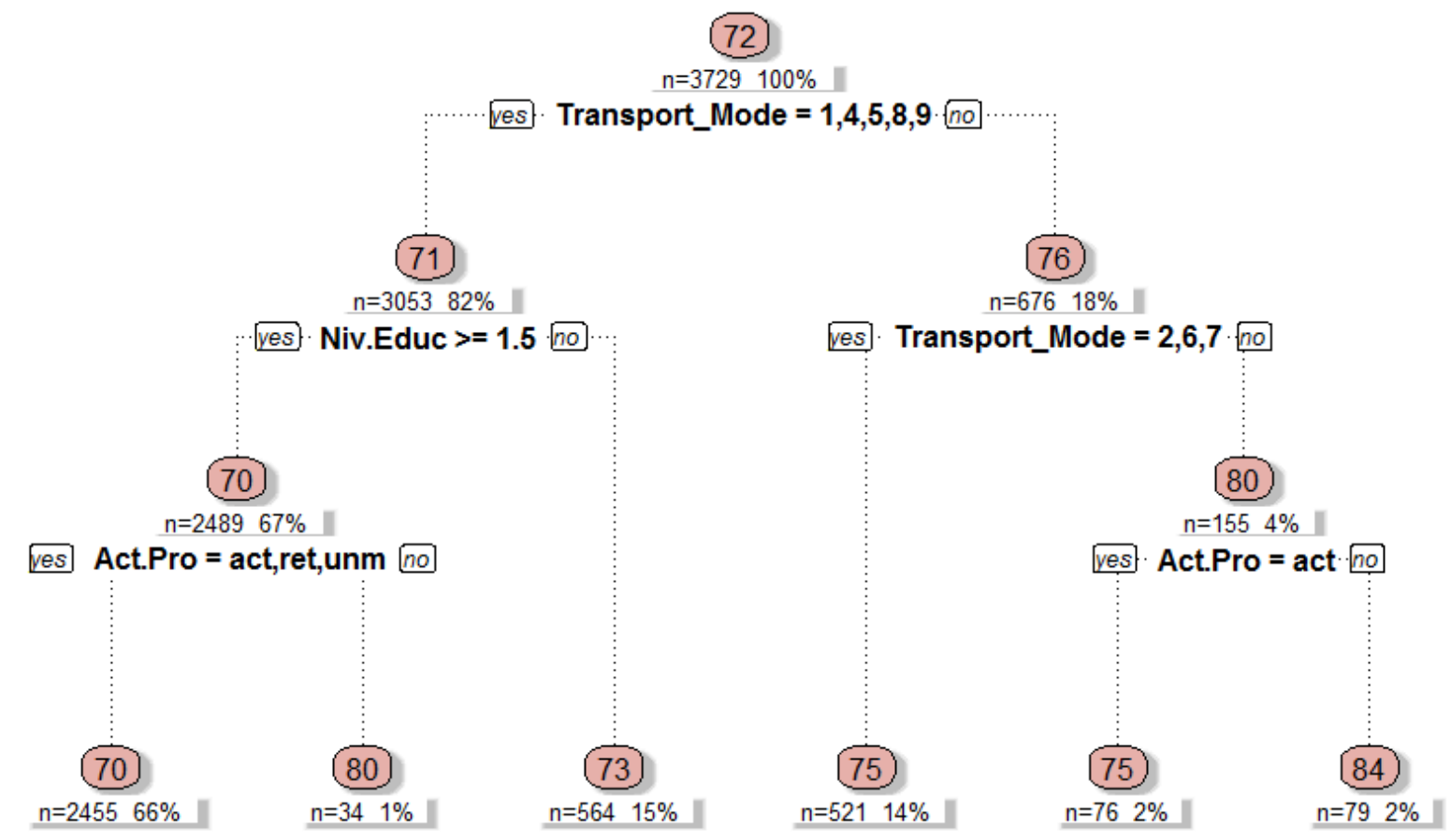

518 This decision tree is constructed for illustrative purposes only, built with the package 'rpart' (Therneau et al., 2015)

519 using the ANOVA method for continuous outcome variables and default parameters. Predictors: sex, transport 520 mode, employment status, educational level. Outcome: $\mathrm{L}_{\text {Aeq, } \mathrm{T}}$ in $\mathrm{dB}(\mathrm{A})$, at trip-stage level. The values in each node 521 represents the estimated for the subgroup.

522

523

524

525

526 